\title{
Sensory conduction in peroneal and posterior tibial nerves using averaging techniques
}

\author{
R. E. LOVELACE, S. J. MYERS, AND L. ZABLOW \\ From the Neurological Clinical Research Centre, Neurological Institute of New York and the Departments \\ of Neurology and Rehabilitation Medicine, College of Physicians and Surgeons, Columbia University, \\ New York, N.Y. 10032, U.S.A.
}

SUMMARY A method of obtaining pure sensory nerve conduction velocities in the lower extremities is described. This involves the use of electronic summation (signal averaging). Potentials were obtained and velocities calculated from all normal subjects examined. In patients with peripheral neuropathies it was often possible to obtain nerve velocities with signal amplitudes as low as $0 \cdot 1 \mu \mathrm{V}$ and these were often slower than those obtained from the normal subjects. The advantages and disadvantages of this method are discussed. It is of significant clinical value in that pure sensory nerve conduction velocities can be measured in the legs when this may be the only valuable parameter in the absence of motor involvement. In addition, investigation of neuropathies at an earlier stage of development and recovery may be facilitated. It is hoped that in the future this technique of obtaining low amplitude responses with an analogue averager can be incorporated with the more routin $\bar{\Phi}$ aspects of nerve conduction testing when clinically indicated.

Information concerning the physiological state of human sensory nerve fibres can be obtained by direct recording of nerve action potentials and computation of their conduction velocities. This is in contrast with the more indirect method of computing motor nerve conduction velocities by recording evoked muscle action potentials. Digital sensory stimulation gives rise to pure sensory nerve action potentials. In the arms these can be recorded with varying degrees of difficulty by proximal surface electrodes. With the exception of the sural nerve (Shiozawa and Mavor, 1969; DiBenedetto, 1970; Cape, 1971), pure sensory nerve conduction velocities in the legs have not been measured for proximal and distal segments with surface electrodes. Distal peroneal (DiBenedetto, 1970; Cape, 1971) and posterior tibial nerve (DiBenedetto, 1970) latencies have, however, been obtained. Using needle recording electrodes Gilliatt et al. (1961) demonstrated that mixed peroneal nerve action potentials could be recorded at the knee after stimulation at the ankle. Mavor and Atcheson (1966) demonstrated similar findings for the posterior tibial nerve using surface recording electrodes at the popliteal fossa. The low amplitude of the recorded potentials necessitated the use of electronig summation (Nuclear Data Enhancetron). Elece tronic summation or averaging has been used bs other investigators for the recording of low voltage human nerve action potentials (Buchthal and Rosenfalck, 1966; Liberson et al., 1966; Behse and Buchthal, 1971). The purpose of this paper is to describe the use of an averaging device to obtain pure peroneal and posterior tibial sensory nerve conduction velocities with surface recording electrodes in normal subjects and in patients with neuropathy.

\section{METHODS}

Using a new 400-ordinate analogue 'averager' developed by the TECA Corporation, it is possible to record sensory nerve action potentials as low in amplitude as $0 \cdot 1 \mu \mathrm{V}$.

The signal from the surface recording electrodes is amplified one thousand times by a Tektronix Type 122 pre-amplifier having a band pass of 8 to $1,000 \mathrm{~Hz} \frac{7}{O}$ and is fed into an oscilloscope with storage facility and also into the 'averager' by way of a Ballantine $N$ model 310-A amplifier whose gain is adjustable in steps of 10. The averager consists of a bank of 400 matched capacitors which are successively charged 
Tektronix 564

Catbode Ray Oscilloscope

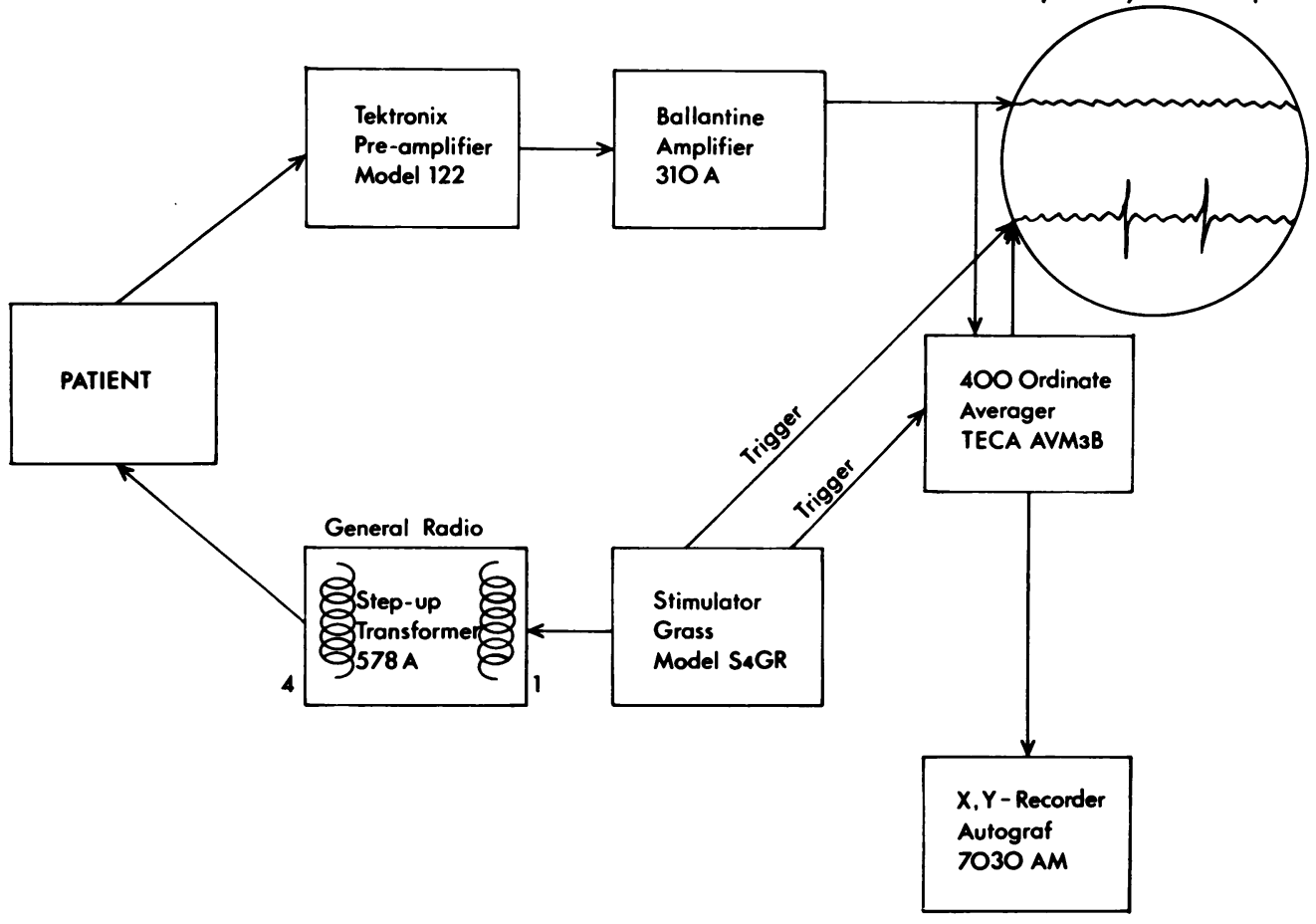

FIG. 1. Schematic representation of sensory stimulation-signal averaging apparatus.

TABLE 1

NORMAL SERIES: PERONEAL NERVE CONDUCTION VELOCITY (ANKLE TO KNEE)

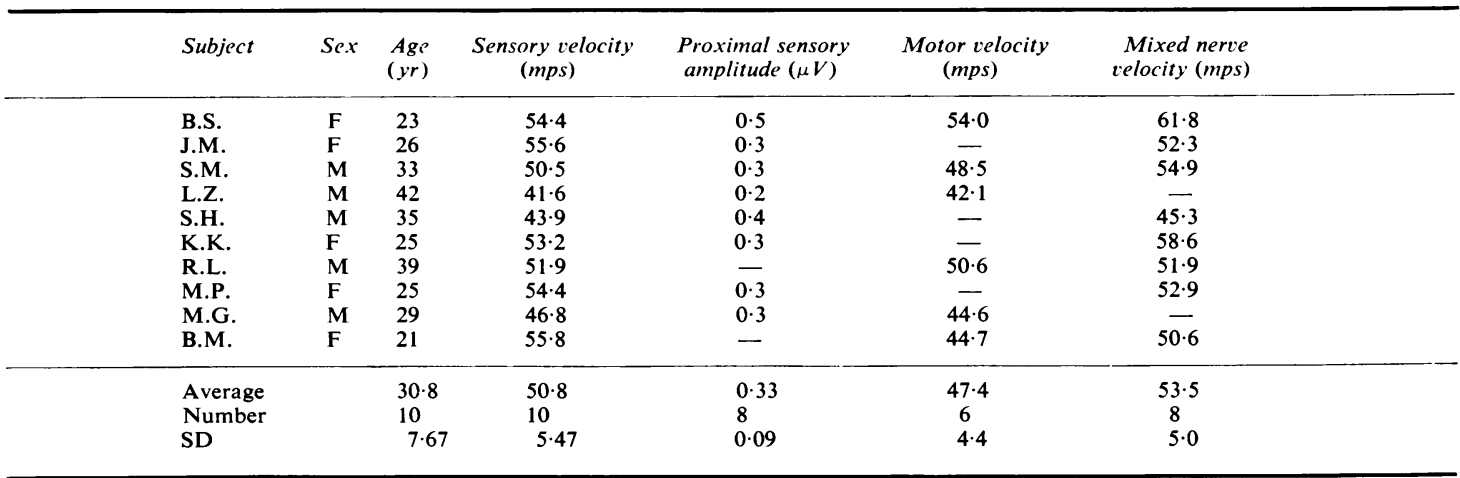

Sensory velocities were measured from the initial ncgative peaks of the evoked potentials, while motor velocities and mixed nerve values were taken from the onset.

eraged

Data 

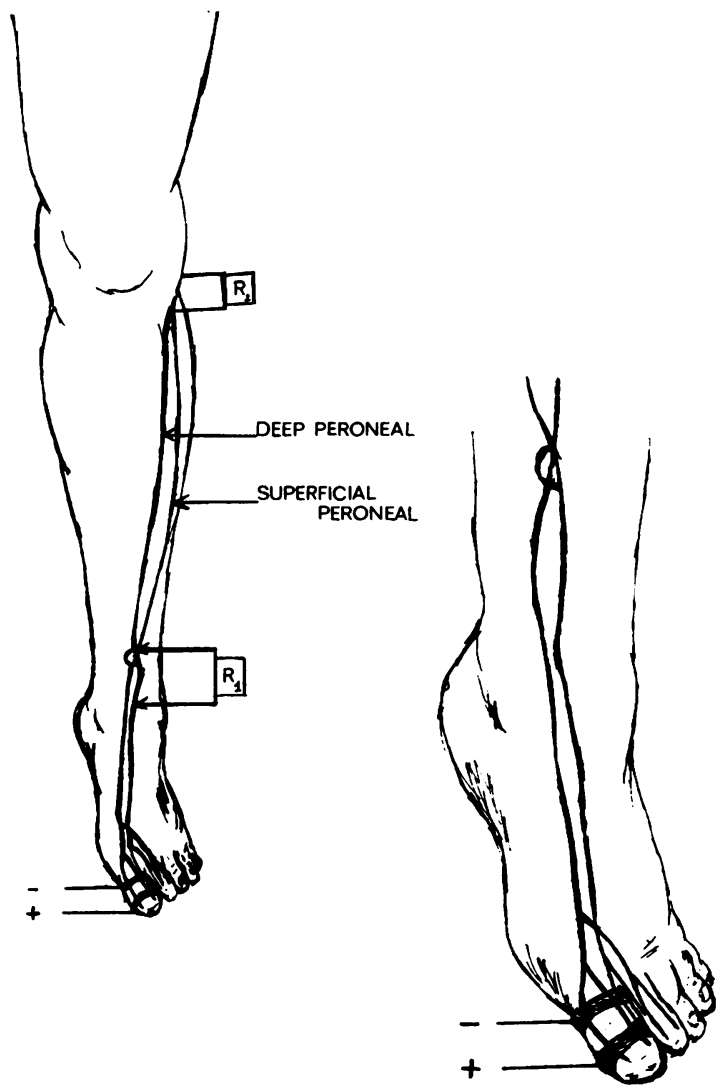

FIG. 2. The peroneal nerve is stimulated at the base of the first phalanx. Surface recording electrodes are over the nerve areas supplied by both deep and superficial branches at the ankle $\left(\mathrm{R}_{1}\right)$ and knee $\left(\mathrm{R}_{2}\right)$.

by a current source driven by the input signal after each trigger, an individual condenser receiving the signal during the same epoch after each stimulus. The trigger is from a Grass stimulator at a rate of up to three per second. The stimulator output to the subject is isolated from ground by a shielded, low capacitance transformer. To present the averaged response, the accumulated condenser voltages are sampled in the same sequence and presented on a second trace of the oscilloscope. When a preset number of sweeps has produced a summated signal which is readable, this signal is then written out on an $\mathrm{x}, \mathrm{y}$ recorder, giving a graphed response (Fig. 1).

Accurate location of the surface markings of the nerve between toe and knee is essential, the recording points being established by prior stimulation of the motor fibres using conical stainless steel electrodes of a large apex angle separated by $3 \mathrm{~cm}$. It is occasionally necessary to readjust the position of the ground and proximal recording electrode on the subject to minimize the stimulus artefact so that the distal response can be defined clearly.

Recording is via the two slightly pointed circular electrodes used for the nerve localization, but silver strips $2 \mathrm{~cm}$ long can also be used satisfactorily (Shiozawa and Mavor, 1969). After scarification,

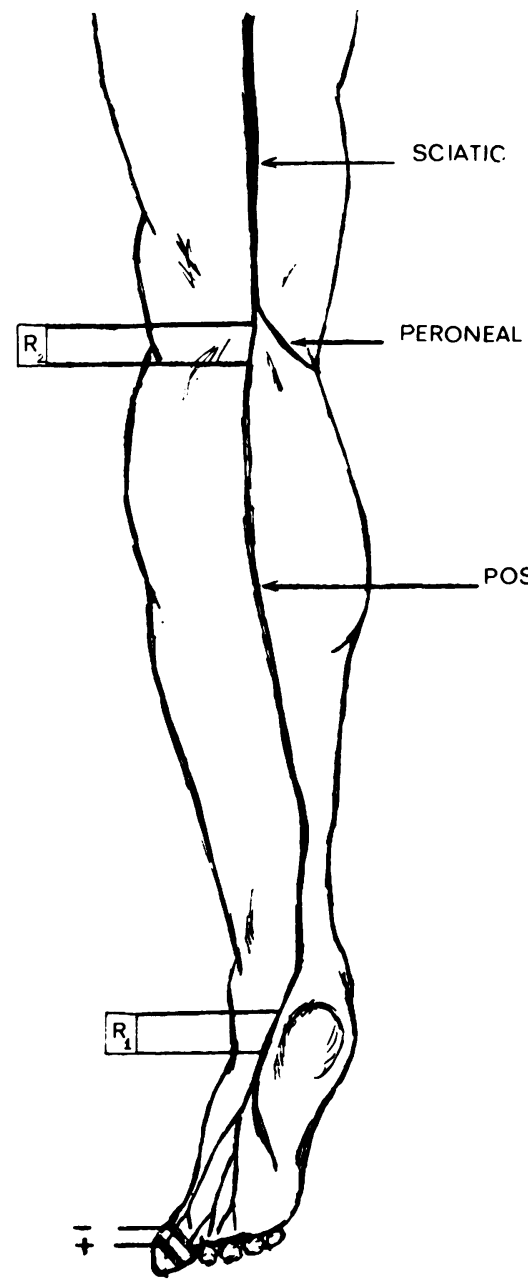

POSTERIOR TIBIAI

FIG. 3. The posterior tibial nerve is stimulated at the base of the first phalanx. The 'watch band' type electrode enables the peroneal fibres dorsally and the posterior tibial fibres ventrally to be stimulated N without changing electrodes. Surface recording electrodes are placed over the nerve at the medial malleolus $\left(\mathbf{R}_{1}\right)$ and popliteal fossa $\left(\mathbf{R}_{2}\right)$. 


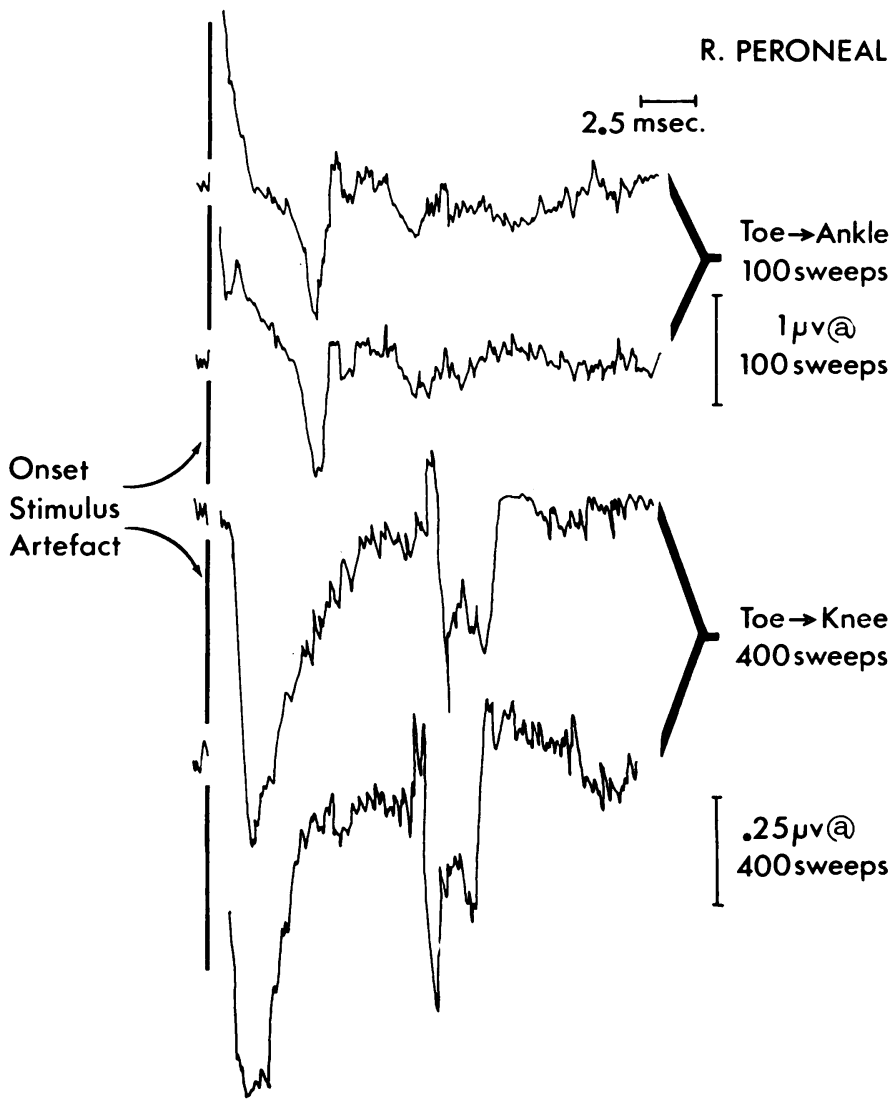

FIG. 4. Averaged proximal and distal responses to stimulation of the peroneal sensory fibres in a normal subject. Two separate runs for toe-ankle and toeknee stimulation are shown to demonstrate reproducibility of responses. Measurements are from peaks of initial negative (downward) response. The large initial peak in the proximal recordings is the stimulus artefact.

TABLE 2

NORMAL SERIES: POSTERIOR TIBIAL NERVE CONDUCTION VELOCITY (ANKLE TO KNEE)

\begin{tabular}{|c|c|c|c|c|c|c|}
\hline Subject & Sex & $\begin{array}{l}\text { Age } \\
(y r)\end{array}$ & $\begin{array}{l}\text { Sensory velocity } \\
\text { (mps) }\end{array}$ & $\begin{array}{l}\text { Proximal sensory } \\
\text { amplitude }(\mu V)\end{array}$ & $\begin{array}{l}\text { Motor velocity } \\
\text { (nips) }\end{array}$ & $\begin{array}{l}\text { Mixed nerve } \\
\text { relocity (mps) }\end{array}$ \\
\hline B.S. & $\mathrm{F}$ & 23 & $52 \cdot 1$ & 0.3 & $51 \cdot 7$ & $57 \cdot 7$ \\
\hline J.M. & $\mathrm{F}$ & 26 & $48 \cdot 4$ & $0 \cdot 3$ & - & $55 \cdot 3$ \\
\hline S.M. & $\mathbf{M}$ & 33 & $50 \cdot 2$ & 0.4 & $44 \cdot 0$ & $54 \cdot 4$ \\
\hline L.Z.. & $\mathbf{M}$ & 42 & $52 \cdot 0$ & 0.3 & $40 \cdot 5$ & $55 \cdot 7$ \\
\hline S.H. & $\mathbf{M}$ & 35 & $45 \cdot 3$ & 0.2 & - & $56 \cdot 6$ \\
\hline K.K. & $\mathbf{F}$ & 25 & $51 \cdot 3$ & $0 \cdot \overline{2}$ & - & $58 \cdot 6$ \\
\hline R.L. & $\mathbf{M}$ & 39 & 51.9 & - & $38 \cdot 6$ & 51.9 \\
\hline M.P. & $\mathrm{F}$ & 25 & $47 \cdot 7$ & 0.3 & - & $51 \cdot 9$ \\
\hline M.G. & $\mathbf{M}$ & 34 & $47 \cdot 6$ & 0.4 & $51 \cdot 3$ & - \\
\hline B.M. & $\mathbf{F}$ & 21 & $50 \cdot 0$ & - & $47 \cdot 1$ & $50 \cdot 0$ \\
\hline Average & & $30 \cdot 3$ & $49 \cdot 7$ & 0.3 & $45 \cdot 5$ & $54 \cdot 7$ \\
\hline Number & & 10 & 10 & 8 & 6 & 9 \\
\hline SD & & $7 \cdot 2$ & $2 \cdot 3$ & 0.8 & $5 \cdot 47$ & $2 \cdot 9$ \\
\hline
\end{tabular}




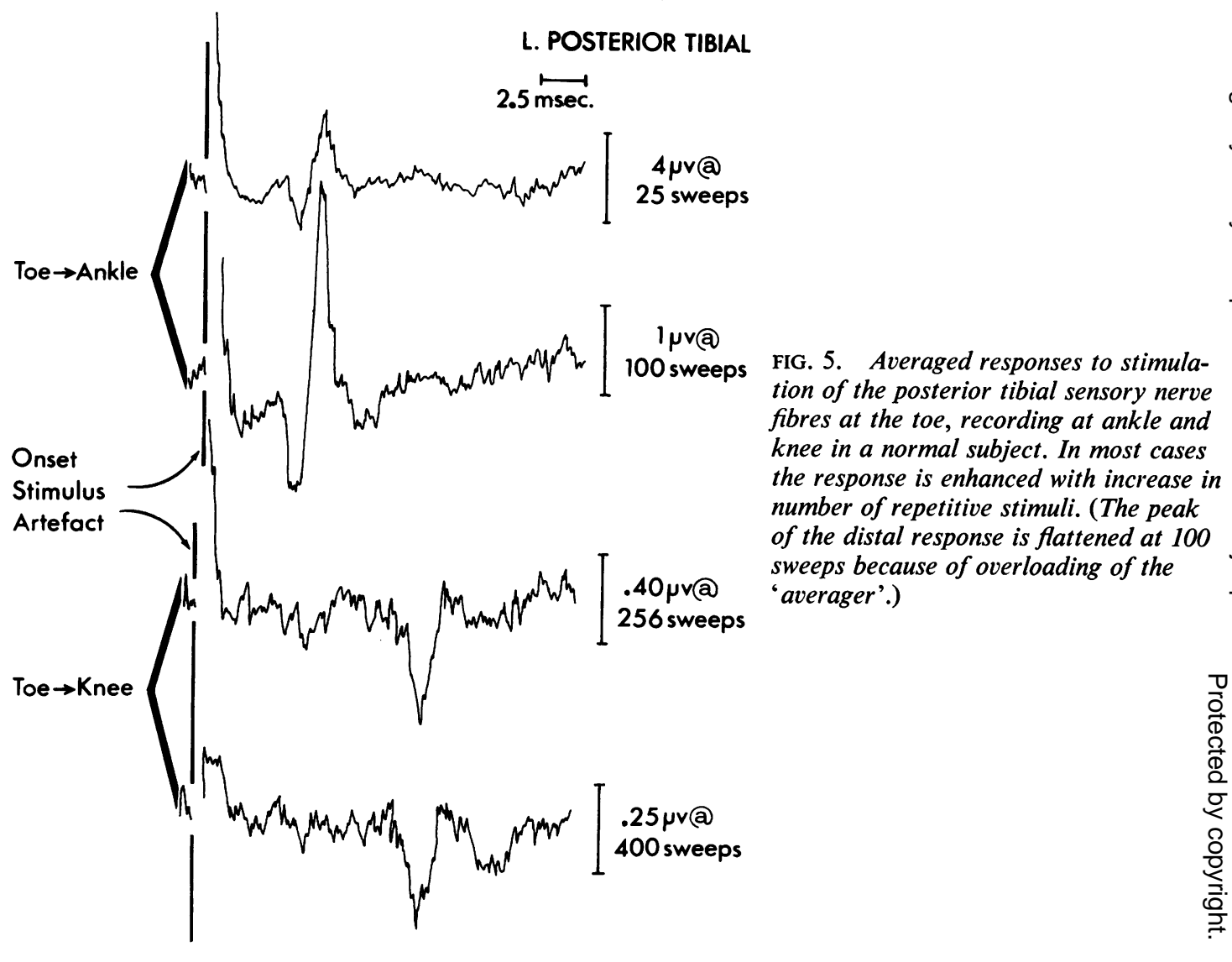

TABLE 3

PATIENT SERIES: PERONEAL NERVE VELOCITY (ANKLE TO KNEE)

\begin{tabular}{|c|c|c|c|c|c|c|c|}
\hline Patient & $\operatorname{Sex}$ & $\begin{array}{l}\text { Age } \\
(y r)\end{array}$ & Diagnosis & $\begin{array}{l}\text { Sensory velocity } \\
\text { (mps) }\end{array}$ & $\begin{array}{c}\text { Amplitude } \\
(\mu V)\end{array}$ & $\begin{array}{l}\text { Motor velocity } \\
\text { (mps) }\end{array}$ & $\begin{array}{c}\text { Mixed nerve } \\
\text { velocity (mps) }\end{array}$ \\
\hline 1 & $\mathbf{M}$ & 31 & INH neuropathy & $44 \cdot 0$ & $0 \cdot 1$ & $42 \cdot 9$ & $39 \cdot 2$ \\
\hline 2 & $\mathbf{M}$ & 54 & Carcinomatous neuropathy & NR & - & $35 \cdot 5$ & - \\
\hline 3 & $\mathbf{M}$ & 40 & Charcot-Marie-Tooth & NR & - & $17 \cdot 5$ & - \\
\hline 4 & $\mathbf{F}$ & 41 & Porphyria & $36 \cdot 4$ & $0 \cdot 3$ & $43 \cdot 5$ & $51 \cdot 3$ \\
\hline 5 & $\mathbf{F}$ & 23 & Diabetes mellitus & $48 \cdot 6$ & $0 \cdot 1$ & $45 \cdot 8$ & $56 \cdot 7$ \\
\hline 6 & $\mathbf{M}$ & 64 & Diabetes mellitus & NR & - & $29 \cdot 1$ & - \\
\hline 8 & $\mathbf{F}$ & 52 & Neuropathy (?ALS) & $38 \cdot 6$ & $0 \cdot 2$ & $48 \cdot 3$ & $48 \cdot 3$ \\
\hline 9 & $\mathbf{M}$ & 54 & Idiopathic sensory neuropathy & $25 \cdot 5$ & - & $42 \cdot 3$ & $39 \cdot 0$ \\
\hline 10 & $\mathbf{F}$ & 16 & Friedreich's ataxia & $39 \cdot 7$ & $0 \cdot 1$ & $44 \cdot 1$ & - \\
\hline 11 & $\mathbf{F}$ & 26 & Diphenylhydantoin neuropathy & NR & - & $42 \cdot 7$ & - \\
\hline Average & & $41 \cdot 8$ & & $38 \cdot 8$ & $0 \cdot 16$ & $39 \cdot 1$ & $46 \cdot 9$ \\
\hline Number & & 11 & & 6 & 5 & 10 & 5 \\
\hline SD & & $16 \cdot 1$ & & $7 \cdot 83$ & 0.09 & $9 \cdot 37$ & $7 \cdot 73$ \\
\hline
\end{tabular}

$\mathrm{INH}=$ Isonicotinic acid hydrazide, isoniazid. ALS $=$ Amyotrophic lateral sclerosis. $\mathrm{NR}=$ No response. 


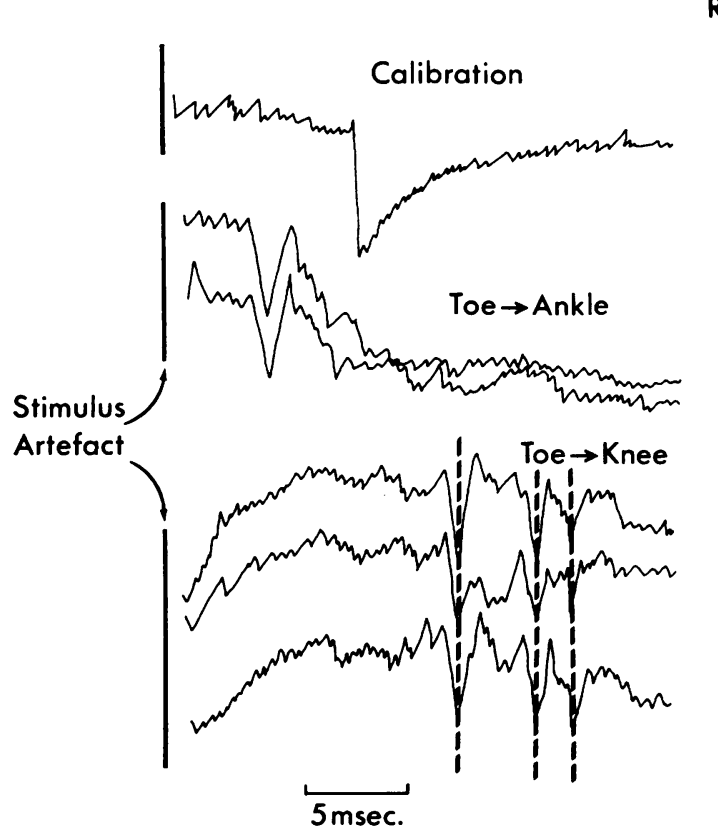

skin resistance is approximately $2,000 \Omega$, while, with careful cleaning only, it is uniformly around $50,000 \Omega$. As results are equivalent by either method, scarification is rarely employed. Sensory nerve fibres at the base of the large toe are stimulated using circular ring electrodes of contracting 'watch-band' type (TECA Corporation). This enables peroneal nerve fibres at the dorsal surface and posterior tibial nerve fibres ventrally to be stimulated from a single electrode. In order to obtain readable potentials, it is necessary to average up to 400 sweeps. At some locations over the nerve a significantly smaller number of sweeps is required. The frequency of stimulation is that maximally tolerated without undue discomfort, usually 3 impulses per second. Time and amplitude calibrations are also averaged and presented on the $\mathrm{x}, \mathrm{y}$ recorder. By these means, it is possible to record potentials as low in amplitude as $0 \cdot 1 \mu \mathrm{V}$, the limitation arising from leakage and errors of matching of the storage capacitors. Measurements are taken from the peak of the initial negative (downward) response. The techniques for stimulation and recording of the peroneal and posterior tibial nerves are seen in Figs 2 and 3 respectively. Figure 4 shows a normal response to peroneal nerve stimulation at the large toe with knee and ankle recording while Fig. 5 shows normal posterior tibial sensory nerve responses.

There were 10 normal subjects, five males and five
R. PERONEAL

\author{
1 $\mu v$ (a) \\ 100 sweeps
}

100 sweeps

400 sweeps

200 sweeps

FIG. 6. Averaged proximal and distal responses to stimulation of peroneal nerve sensory fibres in case 4 with polyneuropathy. In three separate averages of response at the knee after toe stimulation, the same triphasic response is produced. The calibration, as recorded, is for $1 \mu \mathrm{V}$ at 100 sweeps and would therefore represent $0.5 \mu \mathrm{V}$ at 200 sweeps and $0.25 \mu \mathrm{V}$ at 400 sweeps.

200 sweeps

females, ranging between 21 and 42 years of age. Seventeen patients were examined, eight males and nine females, with ages between 16 and 65 years. Diagnoses are listed in Tables 3 and 4. Skin temperatures were not recorded but measurements were taken in a small screened room in which temperature remained constant at $23.9^{\circ} \mathrm{C}\left(75^{\circ} \mathrm{F}\right)$.

\section{RESULTS}

Sensory conduction velocity in the nerve segment from ankle to knee was obtained by stimulating the interdigital nerves of the big toe, subtracting the distal from the proximal latencies, and dividing by the distance between the knee and ankle recording electrodes. In the normal series consistent responses were obtained at every attempt. The mean peroneal sensory velocity was 50.88 metres per second (mps) (SD 5.47) with a range of 41.6 to $55.8 \mathrm{mps}$ (Table 1). The mean amplitude of the peroneal nerve action potential was $0.33 \mu \mathrm{V}$ (SD 0.09) with a range of 0.2 to $0.5 \mu \mathrm{V}$ demonstrating that submicrovolt potentials can be visualized consistently. Using the same averaging techniques, motor nerve conduction in the peroneal nerve 
TABLE 4

PATIENT SERIES: POSTERIOR TIBIAL NERVE VELOCITY (ANKLE TO KNEE)

\begin{tabular}{|c|c|c|c|c|c|c|c|}
\hline Patient & Sex & $\begin{array}{l}\text { Age } \\
y r)\end{array}$ & Diagnosis & $\begin{array}{l}\text { Sensory velocity } \\
\text { (mps) }\end{array}$ & $\begin{array}{c}\text { Amplitude } \\
(\mu V)\end{array}$ & $\begin{array}{l}\text { Motor velocity } \\
\text { (mps) }\end{array}$ & $\begin{array}{c}\text { Mixed nerve } \\
\text { velocity (mps) }\end{array}$ \\
\hline 11 & $\mathbf{F}$ & 26 & Diphenylhydantoin neuropathy & $36 \cdot 2$ & - & $45 \cdot 3$ & - \\
\hline 12 & $\mathbf{F}$ & 42 & Friedreich's ataxia & NR & - & $35 \cdot 0$ & - \\
\hline 13 & $\mathbf{F}$ & 64 & Polyneuropathy & NR & - & $38 \cdot 0$ & - \\
\hline 14 & $\mathbf{M}$ & 65 & Polyneuropathy & $37 \cdot 5$ & 一 & $39 \cdot 5$ & $33 \cdot 7$ \\
\hline 9 & $\mathbf{M}$ & 54 & Idiopathic sensory neuropathy & NR & - & $43 \cdot 6$ & $39 \cdot 3$ \\
\hline 15 & $\mathbf{F}$ & 47 & Polyneuropathy & NR & 一 & $38 \cdot 9$ & - \\
\hline 16 & $\mathbf{M}$ & 22 & Charcot-Marie-Tooth & NR & - & $37 \cdot 9$ & - \\
\hline 17 & $\mathbf{M}$ & 57 & Diabetes mellitus & $27 \cdot 0$ & 0.2 & $40 \cdot 0$ & - \\
\hline 5 & $\mathbf{F}$ & 23 & Diphenylhydantoin neuropathy & $38 \cdot 4$ & $0 \cdot 1$ & $46 \cdot 8$ & $45 \cdot 6$ \\
\hline 1 & $\mathbf{M}$ & 31 & INH neuropathy & NR & - & $29 \cdot 7$ & - \\
\hline Average & & $43 \cdot 1$ & & $34 \cdot 8$ & $0 \cdot 15$ & $39 \cdot 5$ & $39 \cdot 5$ \\
\hline Number & & 10 & & 4 & 2 & 10 & 3 \\
\hline $\mathrm{SD}$ & & 16.8 & & $5 \cdot 26$ & 0.07 & 5.01 & 5.95 \\
\hline
\end{tabular}

gave a mean value in the six normal subjects studied of $47.4 \mathrm{mps}$ (SD 4.71), ranging from a low of 42.1 to a maximum of $54.0 \mathrm{mps}$. The peroneal mixed motor and sensory nerve conduction velocity obtained by stimulating the nerve at the ankle and recording at the knee with surface electrodes gave a mean velocity of 53.5 mps (SD 5.0), for eight of the 10 normal subjects studied, varying between 45.3 and $61.8 \mathrm{mps}$.

Similar recording from the posterior tibial sensory fibres gave a mean velocity of $49.7 \mathrm{mps}$ (SD 2.3) with a range of 45.3 to $52 \cdot 1 \mathrm{mps}$ (Table 2). A mean amplitude of nerve action potentials at the knee of $0.3 \mu \mathrm{V}$ (SD 0.08) was found in eight subjects studied with a range of 0.2 to 0.4 $\mu \mathrm{V}$, similar to that in the peroneal nerve. The mean motor conduction velocity, using the same techniques was $45.5 \mathrm{mps}$ (SD 5.47) in six subjects, ranging from 38.6 to $51 \cdot 7$. Nerve to nerve mixed conduction velocity averaged $54.7 \mathrm{mps}$ (SD 2.9) in nine subjects, with a range between 51.9 and $58.6 \mathrm{mps}$.

These techniques were then applied to 17 patients (age range 16-65 years) with various forms of peripheral neuropathy (Tables 3 and 4). Patients with severe clinical neuropathy (cases $2,3,6,7,13$, and 16) often had no evoked response, but those with a mild to moderate disorder had variable responses with nerve action potential amplitudes in the range of 0.1 to $0.3 \mu \mathrm{V}$ at the knee (Fig. 6). Of those with measurable responses, none had severe clinical neuropathy. In the patients with less severe clinical neuropathy, some with borderline and slightly slow motor conduction velocities had clearly slow sensory velocities. For example, case 17 had a posterior tibial nerve motor conduction velocity of $40 \mathrm{mps}$ but a sensory velocity of only $27 \mathrm{mps}$. Similar examples are seen with the posterios tibial nerve studies in case 14 and also for the peroneal nerve in case 4 (Fig. 6). In the latter, slightly slow motor velocity of $43.5 \mathrm{mps}$ is to bE compared with a clearly slow sensory conductiog velocity of $36.4 \mathrm{mps}$. It was interesting that if case 9 , the patient with idiopathic sensory. neuropathy, the peroneal nerve motor conduce tion velocity was only slightly slow at $42.3 \mathrm{mps}$. సे Out of 11 patients in whom peroneal nerve sensory studies were done, values were obtained in six, and in the remaining five there were no recordable nerve action potentials. Out of 10 posterior tibial nerve studies, only four had measurable responses. Computation of conduction velocity was possible in patients with responses, the mean being $38.8 \mathrm{mps}$ (SD 7.83) in the peroneal with a range of 25.5 to $48.6 \mathrm{mps}$ and in the posterior tibial $34.8 \mathrm{mps}$ (SD 5.26) with a range of 27.0 to $38.4 \mathrm{mps}$. These values are considerably slower than the normal mean values and do not include patients with absent nerve action potentials. This latter consideration would tend to make the mean values even slower. The evoked amplitudes were also lower, the mean amplitude of the peroneal nerve sensory action potential at the knee in the patient group being $0 \cdot 16 \mu \mathrm{V}$, while the two action potentials in which o amplitude could be computed for the posterior $N$ tibial nerve averaged $0.15 \mu \mathrm{V}$. 


\section{DISCUSSION}

Sensory nerve action potentials in the lower extremity can be obtained using electronic summation techniques whereby very low amplitude repetitive signals are differentiated from spontaneous random noise. This report describes the use of such 'signal averaging' techniques to obtain pure sensory nerve conduction velocities from the posterior tibial and peroneal nerves. Several averaging systems are now available, most of which use digital storage techniques, but the present system involves the use of banks of condensers for storing information. The random background noise sums more slowly than the constant nerve potential and the evoked response is thereby made visible. In each study it is necessary to provide a signal of known strength which is averaged in a similar fashion to the evoked response so that an appropriate calibration can be obtained.

There are several advantages of an electronic summation method. Although sensory nerve action potentials can often be obtained directly with needle electrodes, the use of surface electrodes eliminates potentially dangerous and painful insertion of needles near peripheral nerves. It enables the recording of potentials of very low amplitude which can be of value in evaluating peripheral motor neuropathy as well as in obtaining sensory nerve potentials. Buchthal and Rosenfalck (1966) and Behse and Buchthal (1971), using needle recording electrodes, describe greater amplitude of nerve action potentials with amplitude reproducibility. However, the present method with surface electrodes also appears to be reproducible. In this study, potentials were obtained from all normal subjects and from patients with neuropathies showing values of amplitude as low as one-tenth of a microvolt without the risk of producing intraneural haematomas.

There are several disadvantages associated with the use of surface electrode techniques. One is the time needed for accurate electrode placement. Technical difficulties such as interference with distal nerve potentials by large stimulus artefacts are troublesome, but judicious placement of ground and positioning of the proximal recording electrode can reduce this problem.

To date we have found this method to be useful mainly in a specially equipped laboratory, and attempts at using the averaging devices attached to routine electrodiagnostic apparatus are being evaluated. Discomfort associated with repetitive stimulation may be a limiting factor as patients with low pain threshold have difficulty in relaxing, producing large muscle 'noise' artefacts which make averaging unreliable. The question of whether a supramaximal response is obtained is raised. The stimulus intensity is the maximum the patient can tolerate without marked discomfort and remains the same for both proximal and distal recording, so that any difference in latency from a non-supramaximal response would tend to be cancelled out, giving reproducible responses.

There appears to be good correlation between absence of sensory nerve action potentials and severe clinical neuropathy. In cases with mild to moderate neuropathy there was a tendency for sensory conduction velocity to slow to a greater degree than the motor velocity. It would therefore appear to be a more sensitive index of a sensory-motor neuropathy than motor conduction studies alone. This is in agreement with studies of sensory distal latencies and nerve action potentials in diabetic (Downie and Newell, 1961) and uraemic (Preswick and Jeremy, 1964) neuropathies in the upper extremity.

It is of interest that the mean mixed nerve conduction velocities were often faster than either motor or sensory velocity alone. It should be recalled, however, that sensory velocity measurements were taken from the peak of the evoked potentials while motor and mixed nerve velocities were calculated from the onset of the initial negative deflection. An alternative explanation is that the faster alpha 1 spindle afferent fibres in the mixed nerve are recorded which would not be activated by direct digital sensory stimulation or be measured in the techniques of direct motor conduction.

We would like to express our appreciation to Miss Karen Kartlie and Mr. Hugo Gomez for technical assistance. This work was supported by grants NB3359 and NB-04083 from the National Institutes of Neurological Diseases and Blindness. The 400 ordinate averager and the sensory stimulating electrodes were constructed by the TECA Corporation. White Plains, New York. 


\section{REFERENCES}

Behse, F., and Buchthal, F. (1971). Normal sensory conduction in the nerves of the leg in man. Journal of Neurology, Neurosurgery, and Psychiatry, 34, 404-414.

Buchthal, F., and Rosenfalck, A. (1966). Evoked action potentials and conduction velocity in human sensory nerves. Brain Research, 3, 1-122.

Cape, C. A. (1971). Sensory nerve action potentials of the peroneal, sural and tibial nerves. American Journal of Physical Medicine, 50, 220-229.

DiBenedetto, M. (1970). Sensory nerve conduction in lower extremity. Archives of Physical Medicine and Rehabilitation, 51, 253-258.

Downie, A. W., and Newell, D. J. (1961). Sensory nerve conduction in patients with diabetes mellitus and controls. Neurology (Minneap.), 11, 876-882.
Gilliatt, R. W., Goodman, H. V., and Willison, R. G. (1961). The recording of lateral popliteal nerve action potentials in man. Journal of Neurology, Neurosurgery, and Psychiatry, 24, 305-318.

Liberson, W. T., Gratzer, M., Zalis, A., and Grabinski, B. (1966). Comparison of conduction velocities of motor and sensory fibers determined by different methods. Archives of Physical Medicine and Rehabilitation, 47, 17-23.

Mavor, H., and Atcheson, J. B. (1966). Posterior tibial nerve conduction. Velocity of sensory and motor fibers. Archives of Neurology, 14, 661-669.

Preswick, G., and Jeremy, D. (1964). Subclinical polyneuropathy in renal insufficiency. Lancet, 2, 731-732.

Shiozawa, R., and Mavor, H. (1969). In vivo human sural nerve action potentials. Journal of Applied Physiology, 26, 623-629. 